Bull. Austral. Math. Soc.

VOL. 69 (2004) [349-349]

\title{
CORRIGENDUM: IRREDUCIBLE DECOMPOSITION OF THE MAGNUS REPRESENTATION OF THE TORELLI GROUP
}

\section{MASAAKI SUZUKI}

Due to a printing error, a significant graph on page 12 was omitted from the paper [1].

\section{LINE 4 ON PAGE 12.}

Thus we obtain

$$
\operatorname{det}\left(B_{i} A_{j}\right)=\frac{\left(1-w_{1}\right)^{2}\left(1-w_{2}\right)^{4} \cdots\left(1-w_{g-1}\right)^{4}\left(1-w_{g}\right)^{2}}{w_{1} w_{2}{ }^{2} \cdots w_{g-1}{ }^{2} w_{g}}
$$

and the associated graph can be expressed as

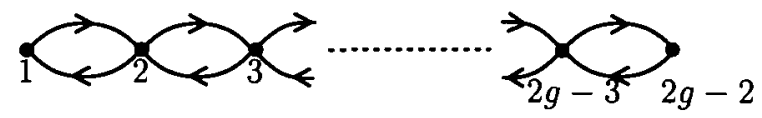

Therefore by virture of Theorem 5.2 , the representation $\left.\rho_{B(z, w)}\right|_{L_{g}}$ is irreducible. Hence $\rho_{B(z, w)}$ and $\rho_{B}$ are irreducible.

\section{REFERENCES}

[1] M. Suzuki, 'Irreducible decomposition of the Magnus representation of the Torelli group', Bull. Austral. Math. Soc. 67 (2003), 1-14.

Graduate School of Mathematical Sciences

University of Tokyo

3-8-1 Komaba

Meguro

Tokyo 153-8914

Japan

Received 25th Setpember, 2003

Copyright Clearance Centre, Inc. Serial-fee code: 0004-9727/04 \$A2.00+0.00. 